\title{
Early diagnosis of tuberculosis in the health services in different regions of Brazil ${ }^{1}$
}

\author{
Tereza Cristina Scatena Villa ${ }^{2}$ \\ Maria Amélia Zanon Ponce ${ }^{3}$ \\ Anneliese Domingues Wysocki ${ }^{4}$ \\ Rubia Laine de Paula Andrade ${ }^{5}$ \\ Tiemi Arakawa ${ }^{6}$ \\ Beatriz Estuque Scatolin ${ }^{4}$
}

\author{
Maria Eugenia Firmino Brunello 6 \\ Aline Ale Beraldo 4 \\ Lucia Marina Scatena ${ }^{7}$ \\ Aline Aparecida Monroe ${ }^{8}$ \\ Reinaldo Antonio da Silva Sobrinho ${ }^{9}$ \\ Lenilde Duarte de Sá10
}

\author{
Jordana de Almeida Nogueira ${ }^{10}$ \\ Marluce Maria de Araújo Assis ${ }^{11}$ \\ Roxana Isabel Cardozo-Gonzales ${ }^{12}$ \\ Pedro Fredemir Palha ${ }^{13}$
}

\begin{abstract}
Objective: To analyze the infected person's first contact with the health services, for the early diagnosis of tuberculosis (TB) in different regions of Brazil. Method: a cross-sectional study undertaken in 6 municipalities in the South-east, South and North-east regions of Brazil. Data collection involved secondary sources and interviews with the patients. The data was analyzed using descriptive techniques and multiple correspondence factor analysis. Results: Primary Health Care (PHC) presented the longest time to diagnosis and the lowest proportion of diagnoses. The services associated with diagnosis in the first consultation were the specialized services and the Tuberculosis Control Programs, which offer consultations and tests on-site. Conclusion: For the control of TB, it is necessary to organize the work in an integrated way between the different services' teams. In Primary Health Care, it is also necessary to observe the extent of incorporation and sustainability in the implementation of these actions into the health services' daily practice.
\end{abstract}

Descriptors: Tuberculosis; Diagnosis; Health Services Evaluation; Primary Health Care.

\footnotetext{
${ }^{1}$ This research was supported by Conselho Nacional de Desenvolvimento Científico e Tecnológico (CNPq), process \# 575386/2008-8 and 558835/2009-0. 2 PhD, Full Professor, Escola de Enfermagem de Ribeirão Preto, Universidade de São Paulo, WHO Collaborating Centre for Nursing Research Development, Brazil. ${ }^{3}$ PhD, Professor, Faculdade Ceres, Brazil.

4 Doctoral Student, Programa Interunidades de Pós-graduação em Enfermagem, Escola de Enfermagem, Universidade de São Paulo and Escola de Enfermagem de Ribeirão Preto, Universidade de São Paulo, WHO Collaborating Centre for Nursing Research Development, SP, Brazil.

${ }^{5} \mathrm{PhD}$, RN, Escola de Enfermagem de Ribeirão Preto, Universidade de São Paulo, WHO Collaborating Centre for Nursing Research Development, SP, Brazil. ${ }^{6}$ Doctoral Student, Escola de Enfermagem de Ribeirão Preto, Universidade de São Paulo, WHO Collaborating Centre for Nursing Research Development, SP, Brazil.

7 PhD, Professor, Universidade Federal do Triângulo Mineiro, Brazil.

8 PhD, Professor, Escola de Enfermagem de Ribeirão Preto, Universidade de São Paulo, WHO Collaborating Centre for Nursing Research Development, Brazil.

$9 \mathrm{PhD}$, Professor, Universidade Estadual do Oeste do Paraná, Brazil.

${ }^{10} \mathrm{PhD}$, Professor, Universidade Federal da Paraíba, Brazil.

${ }_{11} \mathrm{PhD}$, Full Professor, Universidade Estadual de Feira de Santana, Brazil.

$12 \mathrm{PhD}$, Professor, Universidade Federal de Pelotas, Brazil.

13 PhD, Associate Professor, Escola de Enfermagem de Ribeirão Preto, Universidade de São Paulo, WHO Collaborating Centre for Nursing Research Development, Brazil.
}

Corresponding Author:

Tereza Cristina Scatena Villa

Universidade de São Paulo. Escola de Enfermagem de Ribeirão Preto

Av. Bandeirantes, 3900

Bairro Monte Alegre

CEP: 14040-902, Ribeirão Preto, SP, Brasil

E-mail: tite@eerp.usp.br 


\title{
Diagnóstico oportuno da tuberculose nos serviços de saúde de diversas regiões do Brasil
}

Objetivo: analisar o primeiro contato do doente com os serviços de saúde para o diagnóstico oportuno da tuberculose (TB), em diferentes regiões do Brasil. Método: trata-se de estudo de coorte transversal, em 6 municípios das Regiões Sudeste, Sul e Nordeste. Para a coleta utilizaram-se fontes secundárias e entrevista com os doentes. Os dados foram analisados por meio de técnicas descritivas e análise fatorial de correspondência múltipla. Resultados: a Atenção Primária à Saúde apresentou maior tempo e menor proporção de diagnósticos. Os serviços associados ao diagnóstico, na primeira consulta, foram os serviços especializados e os Programas de Controle da TB, que oferecem consulta e exames no próprio local. Conclusão: faz-se necessária a organização do trabalho de forma integrada, entre as equipes dos diferentes serviços, para as ações de controle da TB. Na Atenção Primária à Saúde, é preciso ainda observar o grau de incorporação e sustentabilidade na execução dessas ações à prática diária dos serviços.

Descritores: Tuberculose; Diagnóstico; Avaliação de Serviços de Saúde; Atenção Primária à Saúde.

\section{El diagnóstico oportuno de la tuberculosis en los servicios de salud de varias regiones de Brasil}

\begin{abstract}
Objetivo: Analizar el primer contacto del paciente con los servicios de salud para el diagnóstico oportuno de la tuberculosis (TB) en diferentes regiones de Brasil. Método: Estudio transversal en seis ciudades en el sudeste, sur y noreste. La recolección de datos utilizó fuentes secundarias y entrevistas con los pacientes. Los datos fueron analizados utilizando técnicas descriptivas y el análisis factorial de correspondencias múltiples. Resultados: La Atención Primaria obtuve menor proporción de diagnósticos y mayor tiempo. Los servicios asociados con el diagnóstico en la primera visita fueron los servicios especializados y los Programas de Control de la Tuberculosis, que ofrecen consultas y exámenes in situ. Conclusión: Es necesaria la organización del trabajo integrado entre los equipos de los diferentes servicios para las acciones de control. En la Atención Primaria, es necesario también observar el grado de desarrollo y sostenibilidad en la aplicación de estas medidas a la práctica diaria de los servicios.
\end{abstract}

Descriptores: Tuberculosis; Diagnóstico; Evaluación de los Servicios de Salud; Atención Primaria de la Salud.

\section{Introduction}

Brazil remains among the 22 countries with the highest rate of tuberculosis (TB) in the world(1), with a total of 69,245 cases $^{(2)}$ being presented in 2011 , the second-highest number of infected persons in both of the American continents. Despite the fact that over the last ten years, the disease's incidence rate has reduced by $15.4 \%$ (from 42.8 cases per 100 thousand inhabitants in 2001 to $2.4 / 100,000$ in 2011 ) and mortality by $23.4 \%$ (from 3.1 deaths per 100 thousand inhabitants in 2001, to $2.4 / 100,000$ in 2011), TB remains an important problem for public health.

TB is the fourth largest cause of death from infectious disease, and is the principal cause of death in persons living with $\operatorname{HIV}_{\text {AIDS }}{ }^{(3)}$. The rate of cure in bacilliferous patients is still below that called for $(70.3 \%$ in 2010)(1) and the detection of cases, despite the progressive advances (from $55 \%$ of the cases expected in 2008 to $88 \%$ in 2010$)^{(2)}$, still has gaps, as the rate is calculated based on World Health Organization (WHO) estimates and little is known about the time taken for detection of a suspected case to be confirmed.

Inefficient detection of cases means that individuals continue and will continue to become ill without being identified by the health services, continuously transmitting the disease to other people. Delay in diagnosing $T B$, in addition to affecting the 
bacillus's persistence in society, also influences the infected individuals' prognosis, possibly leading to drug resistance and to death(3).

The difficulties impeding the achievement of efficient detection of cases of TB are more related to how the health services are organized for detecting and treating cases of TB than to the means of diagnosis per $\mathrm{se}^{(4)}$. The multiple factors which lead to delay in the illness's diagnosis and care reflect the complexity of TB control, as they perform an important role, both in aspects intrinsic to the TB patient - which involve the meaning of being ill and the perception of the signs and symptoms - and in access to the health services and to the care received in these places ${ }^{(5-6)}$.

Studies show that the type of health service sought by the TB patient, the type of health service which elucidates the case, and the means of diagnosis used can all be determinant in the problem's resolution time $^{(7)}$.

When one considers the type of health service sought by these individuals the first contact with the health system is focused on which becomes the gateway for them to obtain-care. Care on first contact involves the provision of services which are accessible (a structural or care capacity characteristic) and the use of these services when a care need arises (a characteristic of the process or performance of the care); it may occur at all levels of the system, although it is essentially a characteristic of Primary Health Care $(\mathrm{PHC})^{(8)}$. The TB carrier's first contact - that is, his or her gateway into the health system - is fundamental to ensure access to diagnosis of the disease.

The concept of PHC in the Brazilian context was used as a theoretical framework for the discussion of the present study's results, as it is considered a reordering element in health care and the ideal gateway to the system, it being assumed that it is capable of identifying, diagnosing and treating the cases of TB in the community ${ }^{(9)}$.
In this scenario, TB is considered a chronic condition due to its persistence over time. It enjoins, among many challenges, the early diagnosis of suspected cases, showing the need for the various services which act as gateways to the health services to be enabled for the recognition of health problems ${ }^{(8,10-12)}$.

In Brazil, studies ${ }^{(13-14)}$ have indicated the influence which differences between regions and models of health care organization have on successfully detecting cases of TB and on the disease's appropriate management. In this sense, the performance of the PHC services in the control of the disease shows that the different care models present in the municipalities aggregate local peculiarities (political/organizational/human) which make them heterogenous in the dynamic of dealing with the disease ${ }^{(15-16)}$.

Considering the diversity of the local health systems, the regional disparities and the inequality in terms of access to health services which characterize the Brazilian context, the aim of the study was to analyze the infected person's first contact with the health services for the early diagnosis of TB in different regions of Brazil.

\section{Methods}

This is a cross-sectional study undertaken in six municipalities which are 'priority' for the control of TB. Spread across the South-east, South and North-east regions, they are: Ribeirão Preto (RP) in the state of São Paulo, São José do Rio Preto (SJRP), also in the state of São Paulo, Pelotas (PEL) in the state of Rio Grande do Sul, Foz do Iguaçu (FI) in the state of Paraná, João Pessoa (JP) in the state of Paraíba, and Feira de Santana (FS) in the state of Bahía. These municipalities were chosen deliberately to select differing contexts in the development of TB control actions in local health systems. They were characterized by population, organization of the services which form the gateways to the health system, and by the incidence of TB (Table 1 ).

Table 1 - Characteristics of the municipalities in the study, in relation to population, organization of services which form the gateways to the health system, and incidence of tuberculosis, 2009

\begin{tabular}{|c|c|c|c|c|c|c|}
\hline Characteristics & JP & FS & SJRP & $\mathbf{R P}$ & FI & PEL \\
\hline Region of country & North-east & North-east & South-east & South-east & South & South \\
\hline Municipal population estimated for 2009 & 674,762 & 571,997 & 419,632 & 558,136 & 319,189 & 339,934 \\
\hline Coverage of the Family Health Program (PSF) & $89 \%$ & $49 \%$ & $20 \%$ & $13 \%$ & $33 \%$ & $28 \%$ \\
\hline $\mathrm{N}^{\circ}$ of FHS implemented & $180 \mathrm{FHS}$ & $83 \mathrm{FHS}$ & $14 \mathrm{FHS}$ & $21 \mathrm{FHS}$ & $31 \mathrm{FHS}$ & $28 \mathrm{FHS}$ \\
\hline $\mathrm{N}^{\circ}$ of units in the primary health network & 139 & 14 & 24 & 41 & 33 & 50 \\
\hline $\mathrm{N}^{\circ}$ of emergency departments & 1 & 5 & 5 & 5 & 2 & 5 \\
\hline
\end{tabular}


Table 1 - (continuation)

\begin{tabular}{lcccccc}
\hline \multicolumn{1}{c}{ Characteristics } & JP & FS & SJRP & RP & FI & PEL \\
\hline TB care & D & D & D & C & C & C \\
Incidence of TB & $57.5 / 100,000$ & $33.5 / 100,000$ & $35.1 / 100,000$ & $34.2 / 100,000$ & $42.6 / 100,000$ & $51.2 / 100,000$ \\
\hline
\end{tabular}

FHS - Family Health Strategies; D - Decentralized for Primary Health Care Services; C - Centralized in outpatient centers which are specialized in TB care. Sources: IBGE*, 2009; SINAN**, 2010; Management reports from the municipalities in the study, 2009

To select the study participants, prior to the data collection, a survey was undertaken of the patients under treatment in the areas of the study, between November 2008 and November 2009, using data from SINAN, from the TB-WEB I.T system, and/or from the records of the municipal Tuberculosis Control Programs (TCP). Based on this information, the infected persons who met the inclusion criteria (aged over 18 , resident in the municipalities in the study, and outside the prison system) were contacted and invited to participate in the study. The interview with the TB carrier was held either in the health service premises or in the interviewee's home, at a date and time he or she preferred. The minimum estimated sample for each municipality was calculated using the 'Statistica' program (using the commands Several means, oneway ANOVA) and considering the parameters: number of municipalities $=6$; probability of Type $\mathrm{I}$ error $=$ 0.05 ; probability of Type II error $=0.10$; standardized measure of effect size $=0.2$ (square root of the sum of the squares of the standardized effect divided by the number of degrees of freedom of the effect - RMSSE); non-centralized parameter $=2.4^{(17)}$. Considering $a$ non-response rate of $25 \%$, it was calculated that a minimum of 98 TB carriers per municipality should participate in the study.

A total of 598 subjects $(R P=98, S J R P=99, F I=100$, $\mathrm{PEL}=101, \mathrm{JP}=100, \mathrm{FS}=100)$ accepted to participate in the study, excluding those who could not state which health service they had sought first.

The data was collected between July and November 2009, through the application of a structured questionnaire developed based on the components of the Primary Care Assessment Tool (PCAT), developed and validated for evaluating the critical aspects of $\mathrm{PHC}^{(8)}$. This instrument was adapted and validated for the evaluation of PHC in $\mathrm{Brazil}^{(18)}$ and adapted for TB care ${ }^{(19)}$. The questionnaire aimed to re-construct the ill person's trajectory from the moment of the appearance of the signs and symptoms of TB, through to seeking the health services and diagnosis.
In this study, the health services were grouped and classified according to the organization of the work process, the hours of attendance, the health team's type of professional qualification, and the technological density and complexity for attending the service user:

-Primary Health Care (PHC): made up of the Basic Health Centers (BHC) and Family Health Centers (FHC) and characterized by attending both spontaneous and scheduled demand, functioning in regular business hours, the presence of a generalist team and resources with low technological density;

-Emergency care (EC): made up of emergency departments, and characterized by attendance on demand, functioning 24 hours a day, the presence of an emergency team and medium-density technology, with local diagnostic support (x-ray and laboratory);

-Specialized Services (SE): made up of private clinics and hospitals with the presence of medium and high technological density, specialized teams and diagnostic support;

-Tuberculosis Control Program (TCP) Outpatient Service: specialized outpatient centers for monitoring cases of $\mathrm{TB}$, with the presence of medium technological density, specialized teams and diagnostic support.

The variables used in the study were: first health service visited for the diagnosis; the time which passed between the first visit to the service and the diagnosis (time to diagnosis); diagnoses carried out in the first health service visited; the health service which diagnosed the case, sputum smear requested in the first health service visited; $x$-ray requested in the first health service visited; and the type of service which most requested the sputum smear.

In the descriptive analysis, the variable 'time to diagnosis' was analyzed through the medians and was categorized as delay ( $50 \%$ of the values which precede the median) and non-delay (50\% of the values which succeed the median). The remaining variables were analyzed by frequency distribution.

The multiple correspondence factorial analysis was used to investigate the relationship between the

*IBGE: Brazilian Institute of Geography and Statistics. Translator's note.

**SINAN: The Brazilian National Disease Notification System. Translator's note. 
municipalities in the study and the delay in diagnosis, using the variables: first health service visited; the health service which diagnosed the case; diagnosis in the first health service visited; request for smear test and request for $x$-ray.

This research was approved by the Research Ethics Committee of the Ribeirão Preto College of Nursing (protocol 0984/2008), satisfying the recommendations contained in Resolution 196/96 of the National Health Council - Ministry of Health.

\section{Results}

Based on the interviews, it was found that the health service that the ill people most sought first was the PHC or Emergency Departments. In the municipality of PEL this was split equally between the PHC and SS. FS also stood out because of the demand for the SS. (Table 2).

In relation to the time which passes between the first attendance and the diagnosis, it may be observed that the TCP presented the smallest time, apart from in the municipality of PEL, where a median time of 20 days was identified. It should be emphasized that the longest time found for this interval was 22.5 days, for those patients who visited PHC in SJRP and of 30 days for the individuals who attended PHC in PEL.

It was also identified that all the service users (100\%) who visited TCP as their first health service obtained the diagnosis of TB in the same locale. Among the PHC units, the smallest proportion of diagnoses carried out in the first health service visited was in FS (8.6\%) and the greatest, in SJRP (46.7\%). Among the EC, the smallest proportion was also found in FS (12.5\%) and the largest, in PEL (44.4\%). Among the $\mathrm{SS}$, the smallest proportion found was in $\mathrm{FI}(30.0 \%)$ and the largest in SJRP (80.0\%).

The health service which diagnosed the most cases of TB was the TCP, apart from in SJRP where the majority of diagnoses took place in the SS. In relation to the requesting of diagnostic examinations in the first health service visited, it was observed that the $x$-ray was the examination requested most. The TCP stood out in respect to requesting the smear test.

Table 2 - Distribution of the variables of organization of care, according to the perception of people infected with TB

\begin{tabular}{|c|c|c|c|c|c|c|c|}
\hline \multirow{2}{*}{\multicolumn{2}{|c|}{ Variables / Indicators }} & \multicolumn{6}{|c|}{ Municipalities in study } \\
\hline & & JP & FS & SJRP & $\mathbf{R P}$ & FI & PEL \\
\hline \multirow{4}{*}{$\begin{array}{l}\text { First health service visited for } \\
\text { the diagnosis* }\end{array}$} & $\mathrm{PHC}$ & $47(47.0 \%)$ & $35(35.0 \%)$ & $30(30.3 \%)$ & $22(22.4 \%)$ & $36(36.0 \%)$ & $35(34.7 \%)$ \\
\hline & $\mathrm{EC}$ & - & $16(16.0 \%)$ & $48(48.5 \%)$ & $57(58.2 \%)$ & $36(36.0 \%)$ & $27(26.7 \%)$ \\
\hline & SS & $36(36.0 \%)$ & $40(40.0 \%)$ & $20(20.2 \%)$ & $14(14.3 \%)$ & $20(20.0 \%)$ & $34(33.7 \%)$ \\
\hline & TCPC & $17(17.0 \%)$ & $9(9.0 \%)$ & $1(1.0 \%)$ & $5(5.1 \%)$ & $8(8.0 \%)$ & $5(4.9 \%)$ \\
\hline \multirow{4}{*}{$\begin{array}{l}\text { Time passed between the } \\
\text { first visit to the service and } \\
\text { diagnosis }^{\dagger}\end{array}$} & $\mathrm{PHC}$ & $15[8 ; 30]$ & $15[3 ; 30]$ & $22.5[8 ; 60]$ & $13[2 ; 45]$ & $15[7.5 ; 30]$ & $30[15 ; 60]$ \\
\hline & EC & - & $12.5[6 ; 30]$ & $15[7 ; 30]$ & $7[1.5 ; 20]$ & $12[3 ; 30]$ & $7[1 ; 30]$ \\
\hline & SS & $15[2 ; 52.5]$ & $7[2 ; 15]$ & $12.5[3 ; 45]$ & $11[1 ; 20]$ & $7.5[3.5 ; 37.5]$ & $10[5 ; 30]$ \\
\hline & TCP & $3[1 ; 8]$ & $7[2 ; 15]$ & $6[6 ; 6]$ & $3[1 ; 7]$ & $7[5 ; 25]$ & $20[9 ; 25]$ \\
\hline \multirow{4}{*}{$\begin{array}{l}\text { Proportion of diagnoses } \\
\text { undertaken in the first health } \\
\text { service visited } \ddagger\end{array}$} & $\mathrm{PHC}$ & $16(34.0 \%)$ & $3(8.6 \%)$ & $14(46.7 \%)$ & $6(27.3 \%)$ & $9(25.0 \%)$ & $7(20.6 \%)$ \\
\hline & EC & - & $2(12.5 \%)$ & $8(16.7 \%)$ & $16(28.0 \%)$ & $7(19.4 \%)$ & $12(44.4 \%)$ \\
\hline & SS & $12(33.3 \%)$ & $16(40.0 \%)$ & $16(80.0 \%)$ & $7(50.0 \%)$ & $6(30.0 \%)$ & $15(44.1 \%)$ \\
\hline & $\mathrm{TCP}$ & $17(100.0 \%)$ & $9(100.0 \%)$ & $1(100.0 \%)$ & $5(100.0 \%)$ & $8(100.0 \%)$ & $5(100.0 \%)$ \\
\hline \multirow{4}{*}{$\begin{array}{l}\text { Health service which } \\
\text { diagnosed the case* }\end{array}$} & $\mathrm{PHC}$ & $17(17.0 \%)$ & $4(4.0 \%)$ & $26(26.3 \%)$ & $10(10.2 \%)$ & $10(10.0 \%)$ & $7(6.9 \%)$ \\
\hline & EC & - & $3(3.0 \%)$ & $9(9.1 \%)$ & $26(26.5 \%)$ & $13(13.0 \%)$ & $15(14.9 \%)$ \\
\hline & SS & $28(28.0 \%)$ & $36(36.0 \%)$ & $58(58.6 \%)$ & $30(30.6 \%)$ & $26(26.0 \%)$ & $46(45.5 \%)$ \\
\hline & TCP & $55(55.0 \%)$ & $57(57.0 \%)$ & $6(6.0 \%)$ & $32(32.7 \%)$ & $51(51.0 \%)$ & $33(32.7 \%)$ \\
\hline \multirow{4}{*}{$\begin{array}{l}\text { Proportion of sputum smear } \\
\text { tests requested in the first } \\
\text { health service visited }^{\ddagger}\end{array}$} & $\mathrm{PHC}$ & $26(55.3 \%)$ & $13(37.1 \%)$ & $13(43.3 \%)$ & $14(63.6 \%)$ & $17(47.2 \%)$ & $10(29.4 \%)$ \\
\hline & $\mathrm{EC}$ & - & $3(18.7 \%)$ & $14(29.2 \%)$ & $20(35.1 \%)$ & $17(47.2 \%)$ & $10(37.0 \%)$ \\
\hline & SS & $13(36.1 \%)$ & $12(30.0 \%)$ & $11(55.0 \%)$ & $9(64.3 \%)$ & $6(30.0 \%)$ & $14(41.2 \%)$ \\
\hline & TCP & $17(100.0 \%)$ & $9(100.0 \%)$ & $1(100.0 \%)$ & $4(80.0 \%)$ & $8(100.0 \%)$ & $5(100.0 \%)$ \\
\hline \multirow{4}{*}{$\begin{array}{l}\text { Proportion of x-rays } \\
\text { requested in the first health } \\
\text { service visited }{ }^{\ddagger}\end{array}$} & $\mathrm{PHC}$ & 27 (57.4\%) & $24(68.6 \%)$ & 17 (56.7\%) & $12(54.5 \%)$ & $28(77.8 \%)$ & $19(55.6 \%)$ \\
\hline & $\mathrm{EC}$ & - & $6(37.5 \%)$ & $11(23.0 \%)$ & $47(82.5 \%)$ & $25(69.4 \%)$ & $26(96.3 \%)$ \\
\hline & SS & $25(69.4 \%)$ & 29 (72.5\%) & $15(75.0 \%)$ & $11(78.6 \%)$ & $16(80.0 \%)$ & $22(64.7 \%)$ \\
\hline & $\mathrm{TCP}$ & $16(94.1 \%)$ & $9(100.0 \%)$ & $1(100.0 \%)$ & $5(100.0 \%)$ & $8(100.0 \%)$ & $5(100.0 \%)$ \\
\hline
\end{tabular}

*Percentage calculated based on the number of ill persons interviewed;

+Values referent to the median [interquartile interval];

¥Percentage calculated based on the number of ill people interviewed who visited the type of health service mentioned.

Key: JP - João Pessoa; FS - Feira de Santana; SJRP - São José do Rio Preto; RP - Ribeirão Preto; FI - Foz do Iguaçu; PEL - Pelotas; PHC - Primary Health Care; EC - Emergency Care; SS - Specialized Service; TCP - Tuberculosis Control Program Outpatient Center. 
The application of factorial analysis prioritizes dimensions 1 and 2, with eigen values of 0.315 and 0.249 . By means of Table 3, it was determined which variables belonged to each dimension, according to the greatest absolute contribution $\left(\operatorname{Cos}^{2}\right)$. In this way, dimension 1 was comprised of variables more related to the health services' performance and explains $23.6 \%$ of the data's variability: diagnosis in the first health service visited; request for smear test; and, request for $x$-ray. Dimension 2 was comprised of variables related to the health services, and explains $15.5 \%$ of the data's variability: the first health service visited; and, the health service which diagnosed the case.

The variables selected for dimensions 1 and 2 were localized through coordinates on the factorial plane (Figure 1) and remained represented on this plane. Analyzing the factorial plane, the following associations were observed:
Delay: Municipality of SJRP; Not undertaking diagnostic test in the first health service visited; No request for $x$-ray. Non-delay: Municipality of RP; TCP as first health service visited after the appearance of symptoms of TB; Carrying out of diagnostic test in Emergency Care; Carrying out of diagnostic test in the first health service visited; Request for smear test; Request for x-ray.

On the positive side of dimension 1 "Performance" are the TB carriers in RP, FI and JP, who obtained the diagnosis in the first health service visited and for whom the smear test and $x$-ray examinations were requested, that is, for whom the performance of the TB diagnosis was better.

The favorable position of FI and JP in this dimension does not mean that the health services have excellent conditions of access to the diagnostic tests, in view of the fact that there is no association with non-delay.

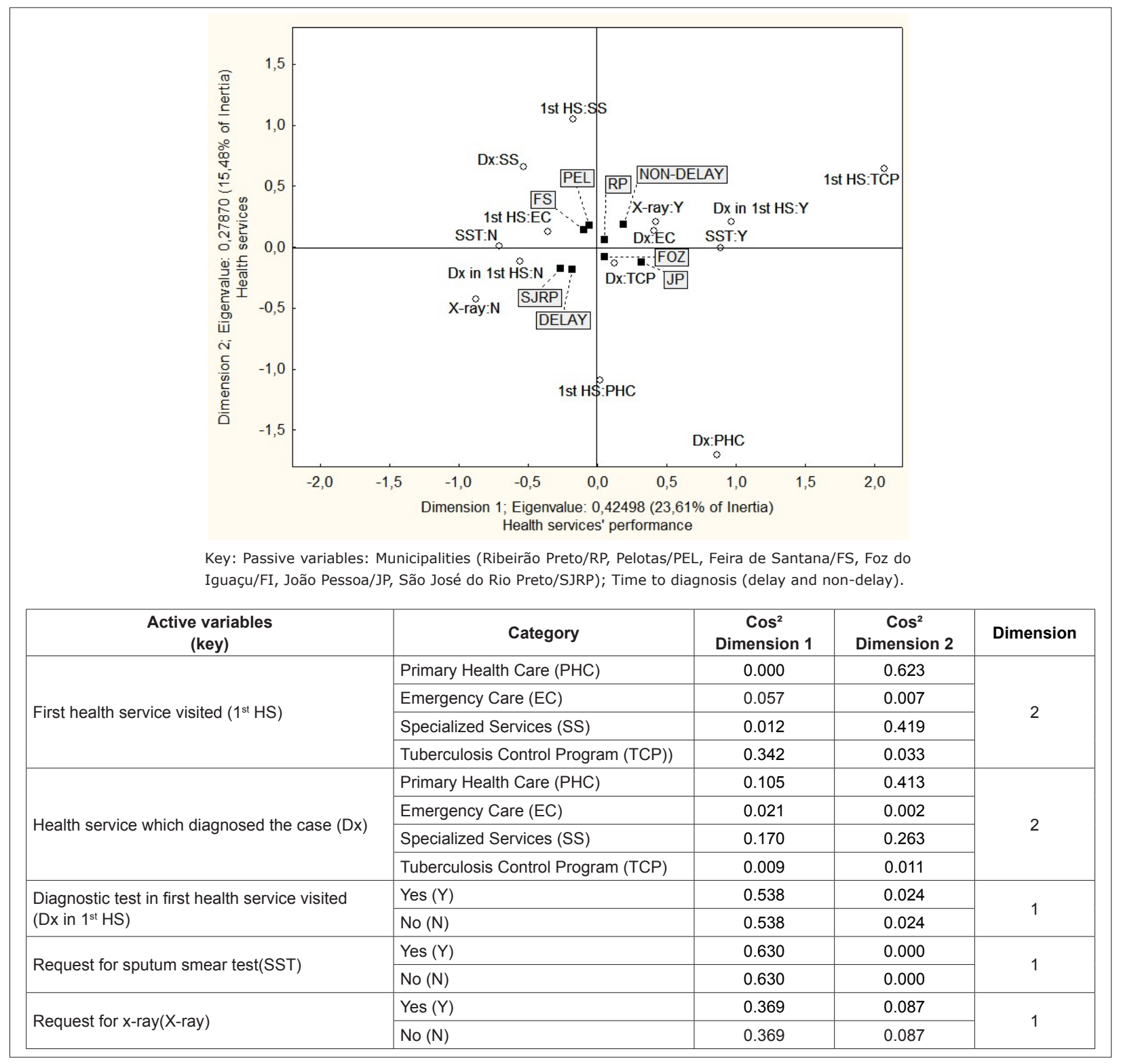

Figure 1 - Factorial plan for evaluating delay in diagnosis of TB in municipalities in different regions of Brazil, 2009 


\section{Discussion}

The literature indicates that the PHC and EC services are the most sought when the symptoms of TB start to appear; however, the hospital system and the private health services are also a gateway for diagnosis of the disease, as some offer direct access to a medical consultation and/or an EC service ${ }^{(5-6,20)}$. In this regard, it stands out that this reality was also found in the present study.

$\mathrm{PHC}$ was less represented in the detection of cases of $\mathrm{TB}$, presenting greater delays and a lower proportion of diagnoses, with the exception of the municipality of SJRP, where this service diagnosed the second-most cases of the disease. It must also be observed that the decentralization of TB care in the municipalities of JP and FS was not decisive in the carrying-out of the diagnosis in PHC, as the TCP was the service which undertook the most diagnoses. In this regard, it may be ascertained that, irrespective of the local health systems' organizational model, whether with high coverage of FHS or with traditional centers, the ability of the primary level to function in the diagnosis of TB depends on the degree of integration and sustainability in the implementation of the actions for controlling the disease in the services' routine practice ${ }^{(21)}$.

It is considered that the use of the PHC is initiated basically by the individuals and that the problems and needs which these present are poorly-defined and need to be recognized(8). Based on this premise, it may be understood that the PHC professionals need to be alert to a wider range of illnesses and threats to health, and that due to this, many cases of TB pass through the service un-noticed.

It should also be emphasized that the biggest delay in diagnosis found in the PHC and in the TCP in PEL may be related to the failures in the laboratory administrative functions, given that the public health network has shortcomings in the logistical and information systems for gathering the sputum samples and dissemination of the results of the exams. Thus, it is evidenced that the health system's organization directly influences the speed with which it diagnoses the illness(22).

The low ability to function of the principal gateways to the health system - the PHC and EC - for diagnosis in the first service visited shows the need for structuring and strengthening the health care network, as well as for training of the health professionals, through implementing continuous education in health ${ }^{(21)}$ such that the initial attendance of the service user may be coherent with the policies prioritizing the control of this disease. It must be observed that for the achievement of the early diagnosis of TB, there are still barriers, which involve the quantitative weakness of human resources, and the high staff turnover and excessive workload in the $\mathrm{PHC}^{(23)}$ and in the EC services.

In relation to the requesting of diagnostic examinations, it was ascertained that $x$-ray is valued to the detriment of the sputum smear test. This situation reflects the inducement of the incorporation of denser and more sophisticated technology in the area of health care, resulting in an onus on the scarce resources destined to the area of health care. In the current context, in spite of the discussion concerning the need to incorporate new technology into TB diagnosis, the sputum smear test still remains a low-cost, essential resource for detecting cases, bearing in mind that it is capable of diagnosing from 60 to $80 \%$ of pulmonary cases. ${ }^{(24)}$.

In the light of the above, it is believed that for the effective control of TB, all of the health services which function as gateways to the system, must be prepared to suspect and diagnose the illness and - principally to determine the flow of service users through the health system - to integrate the services which make up the health care network, such that diagnosis and continuity of care may be ensured.

The fact that only one of the municipalities in the study possessed an I.T system capable of identifying where patients were attended in the health services may be identified as a limitation of the study. Because of this, the study relied only on primary information, supplied by the patients themselves, which may compromise in some way the collection of information due to memory bias. It follows that it is understood that the possibility of complementing the information with secondary records from well-maintained information systems would enrich the research.

\section{Conclusion}

In this study, the PHC and EC services were identified as the principal gateways to the health system, although most of the diagnoses of TB took place in the TCP and SS. In this regard, attention is drawn to the need for the health care network to conform in the distinct scenarios, allowing work to be organized in an integrated way between the services for early diagnosis of TB.

It must also be observed that the present study contributes to the advance of science in the evaluative 
research on health services, since it is focused on operational activities and offers the necessary support for the elaboration of new technical and managerial strategies for optimizing the detection of TB cases in the various parts of the system, by providing knowledge of the types of service which are most searched and how they perform.

\section{References}

1. World Health Organization. WHO report 2011: global tuberculosis control. Geneva: World Health Organization; 2011.

2. Ministério da Saúde (BR). Secretaria de Vigilância em Saúde. Boletim Epidemiológico. Especial Tuberculose, v.43. Brasília (DF): Ministério da Saúde; 2012.

3. Millen SJ, Uys PW, Hargrove J, van Helden PD, Williams BG: The effect of diagnostic delays on the drop-out rate and the total delay to diagnosis of tuberculosis. PLoS ONE. 2008;3(4):e1933.

4. Hino P, Takahashi RF, Bertolozzi MR, Villa TCS, Egry EY. Family health team knowledge concerning the health needs of people with tuberculosis. Rev. Latino-Am. Enfermagem. 2012;20(1):44-51.

5. Oliveira MF, Arcêncio RA, Ruffino Netto A, Scatena LM, Palha PF, Villa TCS. A porta de entrada para o diagnóstico da tuberculose no sistema de saúde de Ribeirão Preto/ SP. Rev Esc Enferm USP. 2011;45(4):898-904.

6. Maciel ELN, Golub JE, Peres RL, Hadad DJ, Fávero $\mathrm{JL}$, Molino LP, et al. Delay in diagnosis of pulmonary tuberculosis at a primary health clinic in Vitoria, Brazil. Int J Tuberc Lung Dis. 2010;14(11):1403-10.

7. Asbroek AHA, Bijlsma MW, Bijlsma MW, Malla $P_{,}$ Shrestha $B$, Delnoij DMJ. The road to tuberculosis treatment in rural Nepal: A qualitative assessment of 26 journeys. BMC Health Services Res. 2008;8(7):1-10. 8. Starfield B. Atenção primária: equilíbrio entre necessidades de saúde, serviços e tecnologia. Brasília (DF): UNESCO; 2002. 726 p.

9. Ministério da Saúde (BR). Secretaria de Atenção à Saúde. Departamento de Atenção Básica. Política nacional de atenção básica. Brasília: Ministério da Saúde; 2006.

10. Díez M, Bleda MJ, Alcaide J, Caloto T, Castells C, Cardenal JI. et al. Determinants of patient delay among tuberculosis cases in Spain. Eur J Public Health. 2004;14(2):151-5.

11. Leung ECC, Leung CC, Tam CM. Delayed presentation and treatment of newly diagnosed pulmonary tuberculosis in Hong Kong. Hong Kong Med J. 2007;13(3):221-7.
12. Santos MAPS, Albuquerque MFPM, Ximenes RAA, Lucana- Silva NLCL, Braga C, Campelo ARL, et al. Risk factors for treatment delay in pulmonary tuberculosis in Recife, Brazil. BMC Public Health. 2005;5(25):1-8.

13. Job JRPP, Gozzano JOA, Bernardes OR Júnior, Garcia $\mathrm{RH}$, Miralhes OJC, Miranda MAP. Informações que antecederam o diagnóstico de tuberculose pulmonar e tempo decorrido até o início do tratamento em pacientes matriculados em Centro de Saúde, São Paulo (Brasil). Rev Saúde Pública. 1986;20(1):21-5.

14. Scatena LM, Villa TCS, Rufino-Netto A, Kritski $A L$, Figueiredo TMRM, Vendramini SHF et al. Acesso ao diagnóstico de tuberculose em cinco municípios do Brasil - análise multivariada. Rev Saúde Publica. 2009;43(3):389-97.

15. Motta MCS, Villa TCS, Golub J, Kritski AL, Ruffino A Netto, Silva DF, et al. Access to tuberculosis diagnosis in Itaborai Municipality - Rio de Janeiro State - Brazil: the patients point of view. Int J Tuberc Lung Dis. 2009;13(9):1137-41.

16. Figueiredo TMRM, Villa TCS, Scatena LM, Cardozo Gonzales RI, Ruffino Netto A, Nogueira JA, et al. Performance of primary healthcare services in tuberculosis control. Rev Saúde Pública. 2009;43(5):825-31.

17. Zar JH. Biostatistical Analysis. New Jersey: Prentice Hall; 2009. 960 p.

18. Almeida C, Macinko J. Validação de uma metodologia de avaliação rápida das características organizacionais e do desempenho dos serviços de atenção básica do Sistema Único de Saúde (SUS) em nível local. Brasília: Organização Pan-Americana da Saúde; 2006.

19. Villa TCS, Ruffino-Netto A. Questionário para avaliação de desempenho de serviços de atenção básica no controle da tuberculose no Brasil. J Bras Pneumol. 2009;35(6):610-2.

20. Silva-Sobrinho RA, Andrade RLP, Ponce MAZ, Wysocki AD, Brunello ME, Scatena LM, et al . Retardo no diagnóstico da tuberculose em município da tríplice fronteira Brasil, Paraguai e Argentina. Rev Panam Salud Publica. 2012;31(6):461-8.

21. Trigueiro JVS, Nogueira JA, SA LD, Palha PF, Villa TCS, Trigueiro DRSG. Controle da Tuberculose: descentralização, planejamento local e especificidades gerenciais. Rev. Latino-Am. Enfermagem. 2011;19(6):1289-96.

22. Barreto ML, Teixeira MG, Bastos FI, Ximenes RAA, Barata RB, Rodrigues LC. Successes and failures in the control of infectious diseases in Brazil: social and environmental context, policies, interventions, and research needs. Lancet. 2011;377(Issue 9780):1877-89. 
23. Monroe AA, Cardozo Gonzales RI, Palha PF, Sassaki CM, Ruffino Netto A, Vendramini SHF, Villa TCS. Envolvimento de equipes da atenção básica à saúde no controle da tuberculose. Rev Esc Enferm USP. 2008;42(2):262-7.

24. Ministério da Saúde (BR). Secretaria Executiva. Secretaria de Vigilância em Saúde. Programa Nacional de Controle da Tuberculose. Manual de recomendações para o controle da tuberculose no Brasil. Brasília (DF): Ministério da Saúde; 2011. 186 p. 